\title{
¿ENQUÉ CONSISTIÓ EL TRIUNFO DEL ESTADO FORESTAL? CONTRACTOR STATE Y LOS ASENTISTAS DE MADERA DEL SIGLO XVIII ${ }^{1}$
}

\section{What did the forestry state's triumph consist of? Contractor State and eighteenth-century timber contractors}

\author{
Rafael TORRES-SÁNCHEZ \\ Universidad de Navarra \\ rtorres@unav.es \\ ORCID: https://orcid.org/0000-0002-6566-4524
}

Oscar RIEZU-ELIZALDE

Universidad de Navarra

oriezu@unav.es

ORCID: https://orcid.org/0000-0002-5739-4413

Fecha de recepción: 22/12/2020

Fecha de aceptación: 03/06/2021

RESUMEN: El artículo revisa la idea tradicional de la construcción de un Estado Forestal y de su supuesto triunfo a mediados del siglo XVIII a partir de la política de suministros de madera para la construcción naval. El objetivo es analizar cómo el progresivo avance en la capacidad legislativa y administrativa del Estado para intervenir en la gestión de los recursos forestales afectó al abastecimiento de madera. Concluimos que el aumento de la autoridad de la Corona sobre los bosques, al imponerse sobre cualquier

1. Este estudio ha sido financiado por Ministerio de Ciencia, Innovación y Universidades del Gobierno de España, en el proyecto PGC2018-096194-B-I00, dirigido por Rafael Torres Sánchez. Investigador Principal y titulado «Guerra, Estado y Sociedad. La movilización de recursos militares en la construcción de la monarquía española en el siglo XVIII».

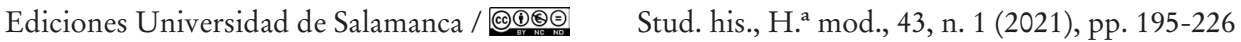


otra jurisdicción, repercutió en la capacidad del Estado de desarrollar políticas de abastecimiento, así como en la modificación de su relación con los proveedores. El Estado español logró durante el siglo XVIII imponer un efectivo monopolio sobre los recursos forestales, que le permitió desarrollar políticas nacionalistas en beneficio de la explotación por sus súbditos, al tiempo que permitió al Estado conceder a los asentistas marcos de actuación más seguros, mediante la imposición y extensión de la autoridad real.

Palabras clave: Estado forestal; Abastecimiento de maderas; Siglo XVIII; Construcción naval; Contractor State.

ABSTRACT: This article rethinks the traditional view of building the forestry state and its ostensible triumph in the mid eighteenth century on the strength of the shipbuilding timber supply policy. The aim is to look at how the steady advance in the state's administrative and legislative capacity, and its concomitant ability to intervene more in forestry policies, affected timber supply. We conclude that the crown's increasing authority over woodland, ousting rival jurisdictions, impinged on the state's capacity of developing supply policies and modifying the crown's relationship with suppliers. During the eighteenth century the Spanish state managed to impose a de facto monopoly over forestry resources, allowing it to draw up nationalist policies to the benefit of its subjects forestry activities, while also allowing the state to set up a surer working framework for its contractors (asentistas) by imposing and extending royal authority.

Keywords: Forestry state; Timber supply; Eighteenth century; Shipbuilding naval; Contractor State.

\section{EL PROBLEMA: EN QUÉ CONSISTIÓ EL TRIUNFO DEL ESTADO FORESTAL}

En el bien conocido estudio de John T. Wing, Roots of Empire. Forests and State Power in Early Modern Spain, c. 1500-1750, el autor desarrolló de forma magistral la tesis de que España llegó a ser durante la Edad Moderna un auténtico Estado Forestal. A partir del estudio de la evolución de la legislación estatal sobre bosques, pudo demostrar que desde el siglo XVI el Estado español fue aumentando su intervención sobre los recursos forestales. El motor de este creciente control del Estado sobre los bosques españoles fue la necesidad de asegurar el abastecimiento 
de maderas para la construcción naval. En esa tesis se demuestra que la legislación permitió al Estado imponer su autoridad sobre el uso público y privado de los recursos madereros, de tal manera que los sucesivos gobiernos pudieron ir extendiendo su control geográficamente por toda la Monarquía, fiscalizar de forma más intensa la conservación de los bosques y adquirir un ingente conocimiento e información sobre las posibilidades y disponibilidad de madera para producción de buques. Hitos legislativos como la Instrucción de Toribio Pérez de Bustamente en 1650 o la Ordenanza de Montes de 1748 avalan la persistente continuidad del esfuerzo de ese Estado Forestal por extender la autoridad real a cualquier bosque de la Monarquía y lograr una completa implantación: «territorialización», en palabras del Wing. Todo ello desembocó en lo que este autor considera «The Triumph of State Forestry», que él mismo sitúa a mediados del siglo XVIII y que le lleva a concluir que «no es una exageración decir que la territorialización de los bosques de España permitió al Estado conseguir madera suficiente para crear la segunda marina de guerra más grande en Europa hacia 1783» (Wing, 2015: 238)2.

Esta interesante tesis ofrece importantes elementos de reflexión, pero también posibilidades de añadir otros enfoques que puedan ayudar a completar su interpretación. La tesis de Wing es heredera de un amplio consenso historiográfico que, centrado más en el siglo XVIII, ha vinculado el derecho del Estado al uso prioritario de la madera de la Monarquía, la «madera del rey», con el acceso al abastecimiento de madera y la evolución de la construcción naval ${ }^{3}$. Con destacada unanimidad, el código forestal de 1748 se ha señalado como la quinta esencia normativa y la prueba del éxito de un Estado capaz de reservarse en régimen de monopolio un recurso militar estratégico y de dotarse de una administración directa para controlar su explotación ${ }^{4}$.

Nuestro artículo se plantea a partir de la pregunta: cómo afectó la construcción y Estado forestal al abastecimiento de maderas, o, dicho de otro modo, fue eficaz el Estado forestal en el objetivo último de garantizar el suministro de madera para la construcción naval. Creemos que constatar la evidencia de una legislación forestal cada vez más intervencionista no es suficiente para comprender la política de abastecimiento de maderas, ni mucho menos su eficacia. Así, por ejemplo, no podemos deducir de las importantes y minuciosas comisiones de inspección de montes desarrolladas desde la década de 1730, que toda esa avalancha de información se tradujese en una mayor eficacia en el suministro maderas para el rey, ni si quiera que

2. La misma tesis en (Martínez, 2015) o en (Trindade, 2015: 57-63).

3. Un eficaz repaso sobre esta bibliografía e historiografía en (Aragón, 2011: 117-140). La interpretación más clásica en (Urteaga, 1987), (Aranda, 1990) y (Pérez, 2006).

4. Una buena e interesante contextualización de este ordenamiento en (Martínez, 2014: 571-602).

Ediciones Universidad de Salamanca / 요 Stud. his., H. ${ }^{a}$ mod., 43, n. 1 (2021), pp. 195-226 
más información forestal se convirtiera en más explotación (Pezzi, 2001: 583-595). Sostener esto sin demostrarlo es arriesgado, porque sería lo mismo que afirmar que la mayor averiguación sobre la riqueza y posibilidades fiscales del siglo XVIII, el catastro de Ensenada, permitió un cambio y mejora en la estructura fiscal (Torres, 2015: 117). Sin lugar a dudas, reunir información era vital para el Estado, pero cómo finalmente se utilizaba en la acción de gobierno puede ser algo muy distinto ${ }^{5}$. Del mismo modo se podía cuestionar que las intenciones conservacionistas de los códigos forestales surgen de una supuesta escasez de madera para la construcción naval en los territorios de la Monarquía española; algo no demostrado para el caso español, y que por los estudios en otros estados europeos es un tema que podría reparar interpretaciones incluso contrarias ${ }^{6}$. No está ni siquiera claro que el origen de la conflictividad y oposición local a la explotación forestal fuese la injerencia estatal, al menos mientras no se estudie la realidad de la demanda estatal en términos de competitividad y coste. Pueblos y particulares podían estar deseosos de atender la demanda estatal, incluso de promover su suministro hacia el Estado, pero siempre que hubiese alguna ventaja, económica o de promoción sociopolítica (Aragón, 2019a: 135-162) (Fernández, 2019: 163-186) .

Parece pues urgente comenzar a comprobar la eficacia del «triunfo» de ese Estado Forestal. Nuestra propuesta es hacerlo centrándonos precisamente en el objetivo principal del Estado Forestal, es decir, el abastecimiento de recursos madereros para las fuerzas armadas. Sin duda, es un tema que requiere importantes esfuerzos de investigación y estudio, principalmente porque cualquier área forestal de la Monarquía Hispánica estuvo activa prácticamente durante todo el siglo XVIII y que la demanda estatal de maderas nunca se interrumpió. Pero también creemos, que, en el estado actual de la vibrante historiografía sobre el uso de la madera en los tiempos modernos, puede tener algún valor empezar a crear un marco de reflexión complementario que ayude a seguir revisando nuestras interpretaciones.

\section{LA ENTRADA DE LOS EXTRANJEROS EN LOS BOSQUES PENINSULARES}

John Wing subrayó la importancia de la persistencia de la normativa forestal en el tránsito al siglo XVIII (Wing, 2015: 163). Efectivamente, varios autores han demostrado que la legislación de los Borbones fue claramente deudora de las leyes

5. Para un ejemplo de cómo se crea, circula y se usa la información en la acción política, véase (Tavárez, 2018: 605-634).

6. Resulta muy sugerente el esfuerzo por contrastar la realidad de los recursos forestales realizado por (Warde, 2006: 28-57). Una aproximación a este enfoque en el caso de México en (Woolley, 2020: 41-71).

7. Una visión amplia de la conflictividad en (Matteson, 2015).

Ediciones Universidad de Salamanca / 요 Stud. his., H. ${ }^{a}$ mod., 43, n. 1 (2021), pp. 195-226 
forestales de los Austria, y que hubo más de continuidad que de cambio (Martínez, 2014: 571-602). Aquí tenemos un primer punto a analizar: ¿la continuidad legislativa forestal en ese periodo fue compatible con un cambio en la política de abastecimiento de madera? Creemos que sí. Como ocurrió también con otros suministros militares, durante el tránsito del siglo XVII al siglo XVIII hubo importantes cambios en el sistema de abastecimiento militar. Aunque el Estado siguió confiando en el recurso a los asentistas para conseguir la práctica totalidad de sus suministros militares, el Estado que demandaba suministros militares, un «contractor state», modificó las relaciones con los proveedores militares y, sobre todo, los objetivos de esa relación. El Contractor State de los Borbones renovó el origen de los contratistas, sustituyendo a los asentistas extranjeros por súbditos del rey. Esta masiva nacionalización de los empresarios militares fue inspirada por ideas mercantilistas, con frecuencia mal definidas, pero con el objetivo claro de que la actividad y gasto en el suministro militar redundase con más claridad en la economía nacional (Torres, 2016b). Veamos cómo este cambio estructural en el sistema de abastecimiento militar pudo afectar al suministro de madera en los años de tránsito al siglo XVIII.

Durante los siglos XVI y XVII, el abastecimiento de maderas para el rey había seguido una evolución similar a la de otros productos militares y pertrechos navales. Las acuciantes necesidades financieras de la Monarquía Hispánica aconsejaron a las autoridades unir la carencia de liquidez de la Real Hacienda con la demanda de pertrechos militares. Esto provocó una selección del tipo de proveedores, asentistas, que podían atender la demanda de suministros del Estado. Solo los grandes hombres de negocios, con fuertes conexiones comerciales, podían participar en el negocio de los abastecimientos militares. El resultado fue una progresiva exclusión de los pequeños asentistas, lo que tuvo una mayor incidencia en los proveedores y productores locales. Los pertrechos militares fueron pasando a manos de los grandes financieros y comerciantes y alejándose de los circuitos nacionales. Los mayores asentistas, además, eran más eficaces si gestionaban los contratos con el gobierno recurriendo a la importación de suministros navales a través de las redes internacionales de comercio. Consecuentemente, el Estado de los Austrias fue adjudicando los contratos de pertrechos navales a las grandes y solventes casas comerciales extranjeras, al tiempo que iba disminuyendo la presencia de los asentistas nacionales y la producción nacional. Franceses, portugueses, genoveses y holandeses se fueron sucediendo en esta dinámica, casi en paralelo con su influencia sobre la hacienda y crédito de la Monarquía ${ }^{8}$.

Durante el último tercio del siglo XVII, la tendencia de conceder a los extranjeros el suministro de pertrechos navales se intensificó con la masiva entrada de los holandeses (Crespo, 2002: 443-468). Hasta entonces habían sido persistentes enemigos

8. La tesis clásica en Thompson. Ejemplos actuales (Trápaga, 2019: 105-134).

Ediciones Universidad de Salamanca / అ@@ Stud. his., H. ${ }^{a}$ mod., 43, n. 1 (2021), pp. 195-226 
de la Monarquía y el comercio de suministros militares con ellos intermitentemente prohibido, pero mientras tanto los Países Bajos también se habían convertido en el mayor mercado de suministros militares del mundo y con el mejor acceso al mercado de maderas del Báltico (Brandon, 2017) (Boterbloem, 2020). La prohibición era una quimera y el Estado español fue aceptando el contrabando y los asientos con testaferros súbditos del monarca y, tras la paz en la década de 1680, autorizando la directa presencia de los holandeses al frente de los contratos de pertrechos navales.

Al evolucionar los contratos de suministros hacia la importación y los proveedores extranjeros, la provisión de maderas para las armadas de los Austrias se fue también alejando de los bosques españoles. La demanda de maderas para la construcción de la Armada del Mar Océano, y su carenado en Cádiz, se cubría principalmente por las redes internacionales controladas por los holandeses y el origen del Báltico (Sanz, 1992: 915-945). En un primer momento, los holandeses utilizaban a testaferros españoles o súbditos de la Monarquía, como los flamencos, amparándose en la trasnacionalidad y «los privilegios de la nación flamenca» (Crespo, 2011: 55-76). Fue el caso, por ejemplo, de Valentín Pérez de Dunslague, pequeño arrendador de impuestos reales en el Puerto de Santamaría, que desde 1665 aseguró durante diez años la provisión de madera y todo tipo de pertrechos navales para la Armada del Mar Océano (Sanz, 1992: 939-940). O el también flamenco Juan Enríquez de Mesa, quien en los años siguientes se convirtió en el mayor proveedor de maderas de la Armada, y hombre de paja de la poderosa casa holandesa de Daniel Vanheden (Serrano, 1983:21-26). En un segundo momento, tras la paz de Munster de 1673, los holandeses aparecen abierta y oficialmente como los directores de las importaciones de maderas como el holandés Laurenzo Overbeecq para Pasajes (Serrano, 1983: 24). Los holandeses podían ahora desplegar todo su potencial de conexión entre el Báltico y la demanda de madera en España. El interés de los comerciantes holandeses no estaba en el contrato de suministro en sí, sino más bien en la intensificación de los circuitos comerciales que se prolongaban hacia el Atlántico y el Mediterráneo, por lo que un contrato de provisión de maderas con el Estado era un medio de acceder a la plata española, imprescindible para seguir comerciando, y un medio de mejorar su acceso al mercado americano?.

Con estos intereses en juego, durante la última década del siglo XVII los holandeses comenzaron a involucrarse aún más en el abastecimiento de madera a la marina española, y no solo con la madera de importación. Los holandeses fueron interesándose directamente en la corta y transporte de madera dentro de la Península. Este nuevo interés podía ser un medio para superar las limitaciones que mostraba entonces la explotación de los recursos forestales peninsulares. La

9. Conforme se iba reduciendo la importación de grano y cereales aumentaba la importación de productos relacionados con la construcción naval, como madera. (Crespo, 2007: 45-76).

Ediciones Universidad de Salamanca / 요 Stud. his., H. ${ }^{a}$ mod., 43, n. 1 (2021), pp. 195-226 
intermitente y reducida construcción naval peninsular de la segunda mitad del siglo XVII (Valdez, 2011), y las ventajosas ofertas de súbditos y particulares recibidas por el rey para producir buques en otras partes de la Monarquía hispana, como Italia o Flandes ${ }^{10}$, limitaban el uso intensivo de los recursos forestales peninsulares. Los escasos incentivos para una explotación nacional, se veían incluso aún más restringidos por el encarecimiento que suponía para el transporte de madera por el interior, la multitud de jurisdicciones, legislaciones y aduanas de la monarquía de los Austria ${ }^{11}$. Las barreras para el tránsito de maderas por el interior aumentaban aún más al llegar al mar, puesto que la distribución de la madera por la costa peninsular era casi imposible por la ausencia de transportes de cabotaje. En estas condiciones, los contratos de suministro de madera tenían un objetivo esencialmente local, de explotación de los bosques más cercanos a los astilleros, como en el Cantábrico o las atarazanas de Barcelona, y, casi siempre, como parte de un asiento de construcción naval ${ }^{12}$ pero su importancia quedaba limitada a una reducida construcción naval (Serrano, 1992: 144) $)^{13}$.

Contratos de explotación concretos, locales y fragmentados en las tareas de corta, arrastre o transporte añadía más incertidumbre y fragilidad. Las propias autoridades no deseaban mantener un sistema de provisión basado en la acumulación de contratos locales, por lo que estaban dispuestas a recibir y apoyar las iniciativas de asentista nacionales que planteaban un horizonte empresarial más amplio. Este fue el caso de Lorenzo de la Bastida en 1678, con la propuesta de un asiento para encargarse de la corta y transporte de madera desde Navarra y Aragón, a través del Ebro, para proveer a los astilleros de Cataluña y Cantábrico ${ }^{14}$. El Estado no dudó en concederle importantes ventajosas condiciones que incluía un área forestal para su uso exclusivo, «el monte de Roeyta, en el Reino de Aragón», y hasta un tiempo

10. Juan Enríquez de Mesa, además de proveedor de maderas, propuso en 1661 construir 16 galeones de 500 toneladas en Galicia, y más tarde la construcción de 24 buques en Ostende, a cambio del privilegio por diez años del corte de palo de Campeche en Yucatán, (Serrano, 1983: 24).

11. Si el problema era aún grave en el siglo XVIII, cabe imaginar que aún lo era más en la etapa anterior. (Aragón, 2017: 41-54).

12. En la construcción de galeones en el Cantábrico era habitual que fuera la misma persona el maestro constructor y proveedor de pertrechos navales (Odriozola, 1998: 93-146). Sirva como ejemplo el caso del asentista bilbaíno Juan de Olaeta en 1679 con el que se contrató la construcción de dos galeones en Mundaca y el corte y provisión de maderas necesarias (Martínez, 2015b: 1208), o el constructor Pedro de Aróztegui, en (Rahn, 2010: 32-35). Para las galeras catalanas, véase (Chamorro, 2019: 374-395).

13. En 1676, por ejemplo, Pascual de Atocha explotaba las maderas del pirineo navarro para la Armada ACA, Consultas y memoriales relativos al comercio en la Corona de Aragón, Consejo de Aragón, Legajos, 0074, n. ${ }^{\circ} 003$.

14. La valoración legal de su contrato en comparación con otros posteriores en (Martínez, 2015b: 1195-1214).

Ediciones Universidad de Salamanca / అ@@ Stud. his., H. ${ }^{a}$ mod., 43, n. 1 (2021), pp. 195-226 
de explotación inusualmente extenso, cuarenta años ${ }^{15}$. Bastida, en compañía con Juan Francisco de Miranda ${ }^{16}$, ofrecía algo esencial para la Junta de Armadas, una provisión integral, esto es, que incluía madera, brea y alquitrán, para un largo plazo y, lo que era igual de importante, encargándose los asentistas de su transporte y distribución. Aunque el Estado aceptó, el asiento se mostró inviable, tuvo varias revisiones, y finalmente se suspendió. Según Álvaro Ruano, el motivo de su fracaso pudo estar en las dificultades del tránsito de la madera por los reinos de la Monarquía, es decir, en las «dificultades jurisdiccionales relacionadas con el cobro de derechos en las aduanas, de saca y entrada en los reinos» (Aragón, 2019b: 429)17. De nuevo, el Estado tuvo que recurrir a compras masivas de madera en Ámsterdam ${ }^{18}$.

Para los holandeses, en cambio, un contrato de provisión de madera peninsular podía ser un negocio muy atractivo. Precisamente en este tipo de contrato podían imponerse respecto a los asentistas españoles porque disponían de más crédito y, sobre todo, liquidez, para soportar las irremediables demoras en los retrasos de pagos de la Real Hacienda. Esto era importante para un planteamiento más integral de todo el proceso del abastecimiento, desde su explotación, corte hasta su transporte y distribución en los astilleros o puertos. Los holandeses podían incluso beneficiarse directamente del transporte de la madera. Precisamente en esas décadas los holandeses habían logrado una destacada posición en el transporte costero del Mediterráneo, ofreciendo sus servicios para conectar los puertos peninsulares entre sí, con el Atlántico y con los italianos y norte de África (Crespo, 2018: 19-49). Esta intensa red de transporte de buques holandeses a lo largo de las costas peninsulares se mantenía activa como medio de compensar el deficitario flete de retorno hacia los mercados de la Europa Septentrional, de hecho, apenas encontraban otros productos para los cargos de vuelta que no fuese sal, vino, aceite o lana (Crespo, 2014: 139-158). Transportar madera española, y otros pertrechos navales españoles, para los astilleros y puertos españoles podía ser para los hombres de negocio holandeses otro medio complementario de compensar el flete de retorno. De alguna manera, las complejidades del comercio internacional empujaban a los holandeses hacia los bosques españoles.

15. AHN, Diversos, Colecciones, 155, n. ${ }^{\circ}$ 19. Consultado en Pares. El proyecto fue presentado a la Junta de Armadas en 1678. No era original, lo había planteado anteriormente el donostiarra Pascual de Atocha, (Goodman, 1997: 201). Sobre la propuesta de Atocha y su viuda Gracia de Atocha para conducir maderas del Pirineo a Tortosa en 1676, véase, ACA, Consejo de Aragón, leg. 74, n. ${ }^{\circ} 3$ (consultado en Pares).

16. Juan Francisco Miranda, natural de Jaca, propuso en 1683 hacerse cargo en exclusiva de este asiento, de «arboles y pertrechos para las Galeras y Armadas... de ser único asentista, o a lo menos tan principal y verdadero como la Bastida», BNE, Porcones, 1431/9.

17. El pago de derechos de salida por la madera cortada y transportada fue una fuente de conflictos, véase, ejemplo en 1682: ACA, Consejo de Aragón, leg. 667, n. 31.

18. Ejemplo de libranzas de pesos a Ámsterdam por compra de madera para la Armada en 1683 (Martínez, 2015b: 1211). 
El transporte de madera era siempre la parte más costosa de una provisión de madera (Torres, 2021), y con frecuencia muy compleja de resolver por la escasez de buques adecuados, el elevado coste de los fletes o los innumerables riesgos para el tráfico marítimo. De hecho, en el asiento de Bastida, se recordará posteriormente la dificultad que afrontó de distribución y que de nada sirvió llevar madera hasta el puerto de Tortosa: «como se ha verificado de haberse perdido en Tortosa grande cantidad de árboles por no haber tenido el asentista en qué transportarlos desde allí a Cádiz» ${ }^{19}$. Para la Junta de Armadas, el transporte de la madera española era un grave problema que superaba a los asentistas locales, y los holandeses ofrecían una solución real.

Todo esto desembocó en una importante propuesta de la casa holandesa de Daniel Vanheden, conocido proveedor de pertrechos navales para la Armada del Mar Océano, y que ahora ofrecía a la Junta de Armadas encargarse directamente de toda la «corta y conducción de árboles de los Pirineos». El proyecto era realmente ambicioso, y aún más significativa la aceptación del Estado de sus condiciones. Vanheden proponía un auténtico monopolio de explotación y transporte de la madera del Pirineo, «de los Montes Pirineos de Aragón y Navarra» ${ }^{20}$. Se ofrecía a encargarse del corte, arrastre y transporte de la madera hasta el puerto de Tortosa, y desde allí también su distribución hacia Cartagena y Cádiz. El Estado, que reconocía que había «poca esperanza que se tiene de que tan gran conveniencia y utilidad para estos reinos se consiga por los medios que ha corrido hasta ahora», no dudó en aceptar sus condiciones. La más importante es que le creaba un marco de estabilidad de treinta años, que suponía un monopolio de facto, puesto «se prohíbe la corta, conducción y venta de árboles para navíos y galeras a otro que no fuere el asentista, y se manda, que los navíos de la Carrera de Indias se provea de estos árboles» En la práctica, el Estado le creaba un marco de privilegios que se extendía por varios reinos: tendría libre tránsito entre reinos y aduanas, de hecho, estaba libre pagar ningún tipo de impuesto, ya fuese local, regnícola o real. Se le concedía el fuero militar para cuatro o más personas que él pusiera al servicio de la explotación, derecho a requisar bueyes y mulas en los pueblos, incluso se le abona un extra para atender a los pagos de madera a los propietarios. El asentista de madera holandés Vanheden ampliaba los privilegios de los asentistas españoles como La Bastida, incluso hereda el bosque particular que se le había concedido, y si en algún momento no era de provecho no debía preocuparse, el Estado «le dará otra merced que equivalga al Monte». Lo sorprendente de este marco de privilegios a un extranjero era que el propio Estado lo asumía con una retórica mercantilista: «al beneficio grande que se seguirá al Real Servicio de establecer en estos Reinos una provisión tan necesaria,

19. AHN, Diversos, Colecciones, 155, n. ${ }^{\circ}$ 19. Madrid 20-3-1697.

20. AGMAB, Madrid, 15-11-1717, Ferrol, leg. 4.

Ediciones Universidad de Salamanca / అ@@ Stud. his., H. ${ }^{a}$ mod., 43, n. 1 (2021), pp. 195-226 
sin necesitar que venga de los Extranjeros». De alguna manera, a finales del siglo XVII se hacía oficial también para el abastecimiento de madera que los extranjeros podían abiertamente participar directamente en la explotación y gestión de los recursos forestales peninsulares ${ }^{21}$.

\section{EL GIRO NACIONALISTA}

La apertura de la explotación de los bosques a compañías holandesas podía haberse convertido en un torrente imparable de iniciativas empresariales holandesas, dada la conjunción de sus propios intereses con los del Estado español, lo que habría modificado considerablemente la narrativa sobre la relación entre Estado y recursos forestales. Si no fue así, y no fue a más, se debió en parte a las circunstancias históricas del inicio del siglo XVIII. Por un lado, el comercio holandés sufrió un serio freno en su actividad internacional y en su acceso al Báltico con la Gran Guerra del Norte (1699-1723). Desde 1699 el comercio internacional holandés se paralizó bruscamente, y la presión de los rusos en las zonas de abastecimiento y mercados holandeses en el Báltico terminaron por bloquear su acceso. Inmediatamente los circuitos desde el Báltico hacia España se paralizaron, y la década de 1701-10 registra el menor número de buques holandeses en el estrecho de Sund con destino a Cádiz (Crespo, 2007: 53). Solventes proveedores de madera holandeses a la Armada tuvieron que incumplir sus contratos con la Casa de la Contratación o con la intendencia de Marina, como fue el caso de la Viuda Wittebol o el conocido Laurenzo Overbeecq, que abandonó Cádiz en 1699 (Crespo, 2007: 63). A este problema internacional se sumó otro acontecimiento que debilitó aún más la continuidad de los negocios holandeses en España. El inicio de la Guerra de Sucesión, y más tras el asedio a Cádiz de 1702, provocó un debilitamiento irremediable de la posición de los asentistas holandeses respecto al gobierno de Felipe. Los holandeses volvían a ser enemigos y no podían estar al frente de una provisión tan estratégica para el Estado como la madera. Las consecuencias para Vandehen no se hicieron esperar. En 1699 pasaba a manos del navarro Juan de Goyeneche en compañía del también navarro José Vidarte, y en octubre de 1703, todo el asiento pasó a manos exclusivas de un español, Juan de Goyeneche ${ }^{22}$.

El tránsito de la titularidad del asiento de provisión de madera a un español ofrece importantes claves. El Estado quiso mantener para el español el monopolio

21. AHN, Diversos, Colecciones, 155, n. ${ }^{\circ}$ 19. Madrid 20-3-1697.

22. AGN, Reales ordenes encargando bajo las condiciones, precios y calidades que se expresan a don Daniel Banbeden el asiento para la conducción de arboles, maderas, brea alquitrán y tablazones de los montes pirineos para las reales armadas y galeras, Reino, Montes, leg. 2, n. ${ }^{\circ} 12,1697$.

Ediciones Universidad de Salamanca / అ@@ Stud. his., H. ${ }^{a}$ mod., 43, n. 1 (2021), pp. 195-226 
de provisión ofrecido al holandés. Parecía claro que había que evitar volver a la situación de incertidumbre que provocaba la dependencia de contractos temporales y una multitud de asientos. El Estado no tuvo ningún problema en reconocerlo como «Provisión General de Árboles mástiles, tablazón, pez rubia o griega, brea o pez negra y alquitrán para apresto de las Armadas y Galeras» ${ }^{23}$, con todos los privilegios concedidos al holandés. Además, y para dejar aún más clara la prioridad que el Estado concedía a la estabilidad del contrato, aceptó otorgar al hombre de negocios español una ampliación en la duración del asiento en otros seis años, es decir, hasta 1733. El modelo de unión de corta, arrastre, transporte y distribución hasta astilleros del asentista holandés era un claro avance para el Estado, y el gobierno de Felipe V aprovechó para ampliarlo y perfeccionarlo. Si la compañía de Daniel Vanheden se comprometía a asumir en el precio pagado por la Real Hacienda el transporte y entrega de madera española directamente en Cádiz y Cartagena, al proveedor Juan de Goyeneche, le añadía más puntos de entrega: Tortosa, Barcelona, Rosas, Alicante, Cartagena, Almería, Granada, Gibraltar, Cádiz, «puertos de Galicia» y «costas de Cantabria». Lo que estaba haciendo el Estado era imponerle al asentista una auténtica distribución nacional. Si el cuello de botella del abastecimiento de madera estaba en su distribución, el Estado acaba de dar un salto cualitativo importante. En adelante, el Estado podía imponer directamente al proveedor general de maderas el lugar de entrega. De alguna manera, por esta vía de forzar los intercambios entre espacios alejados se estaba fomentando un transporte de cabotaje e integrando las economías regionales en un espacio, o mercado, más nacional (Pérez, 2016). A cambio de este progreso, el Estado asumiría parte del coste de su implementación. Aceptó precios diferentes según la distancia al puerto de entrega de las maderas, tomando como punto de partida siempre Tortosa. Así, el precio del codo cúbico entregado podía variar hasta un 50 por ciento desde el Mediterráneo hasta los puertos del Cantábrico: desde los 107 reales por codo en Tortosa hasta los 161 reales de vellón en Pasajes.

La entrada del navarro Goyeneche en este negocio puede ser la conclusión inesperada de la propia estrategia del asentista Vanheden para acceder al interior peninsular y trabajar directamente en los bosques peninsulares. Al menos desde 1687, el holandés utilizó a un navarro, José de Vidarte, como apoderado de su compañía, al que se le unió Juan de Goyeneche (Baroja, 1969: 111)24. La presencia de los navarros parece evidente como medio de introducirse en la zona forestal, pero en concreto la de Goyeneche, podría también estar relacionada con la necesidad del holandés de entrar en los círculos de poder cortesanos, en los que Goyeneche ya mostraba sobradas habilidades (Aquerreta, 2001b: 569-582); (Andujar, 2007: 62-88). La conexión Goyeneche-Vidarte responde también a la lógica de unas conexiones

23. AGMAB, Madrid, 15-11-1717, Ferrol, leg. 4. Viso.

24. Refiere que eran socios. Vidarte estaba asentado en Pamplona. (Aquerreta, 2001a: 102).

Ediciones Universidad de Salamanca / అ@@ Stud. his., H. ${ }^{a}$ mod., 43, n. 1 (2021), pp. 195-226 
particulares entre algunos navarros, de Madrid y Navarra, que utilizaban el flujo de rentas señoriales pertenecientes a nobles castellanos con propiedades en Navarra, como vía de financiación y liquidez para sostener actividades de provisión militar en Navarra, que, al mismo tiempo, se convertían en servicios al Estado y vías de promoción política en Madrid (Torres y Díaz, 2016: 329-344). Lo interesante aquí de esta dinámica de alianzas de élites locales e intereses estatales (Dedieu, 2011: 87-104) es que facilitó la búsqueda de una solución al derrumbamiento de la opción holandesa. La fidelidad de los navarros al gobierno de Felipe V durante la Guerra de Sucesión consolidará y fortalecerá definitivamente la alianza, y con ella la permanencia del monopolio de abastecimiento de madera en manos españolas.

Cabía la posibilidad de que una vez pasada la crisis comercial en el Báltico y con los holandeses, la posición de los navarros fuese cuestionada por la recuperación del poder crediticio de los holandeses. El peligro del retorno de los extranjeros al negocio de la madera incluso se podía ampliar con la entrada de los asentistas franceses, algo que era perfectamente viable dada la creciente influencia de los franceses en los primeros gobiernos de Felipe $\mathrm{V}$ y su presencia en las provisiones militares durante buena parte de la guerra de Sucesión los convertía en serios competidores de los navarros (Dubet, 2008a). De hecho, los franceses estaban comenzando a entrar en los bosques españoles. Desde al menos 1698, ante los graves problemas que tenían los franceses para obtener madera para sus arsenales se empezó a comprar madera en España, en concreto en el Pirineo navarro y catalán ${ }^{25}$. En los años siguientes, la presencia francesa aumentó rápidamente, ahora de la mano de la Orden de Malta y en el pirineo catalán (De Pablo, 2020: 34-44). La Orden de San Juan quería construir navíos en el arsenal de Tolón y disponía de administración en ambos lados de la frontera del Pirineo oriental, el Priorato de Cataluña, con la que organizar la explotación maderera, principalmente en el área de Requesens, financiación y la gestión del transporte hasta Rosas y embarque para Tolón. Varios asentistas franceses se encargaron de contratar con los sanjuanistas la explotación y transporte, que incluso se extendió a Navarra y Aragón (De Pablo, 2020: 44). Es decir, con el cambio dinástico, se hizo real la posibilidad de la entrada de los franceses, lo que hubiera significado una vuelta de los extranjeros al control del abastecimiento de madera para la Armada.

Un elemento que actuó como freno a este retorno de los extranjeros fue la creciente influencia que fueron ganando en las finanzas de Felipe. Una espiral de servicios al Estado y de impagos de la hacienda fue el catalizador de la acumulación de provisiones militares. La condición de fiel súbdito de la Monarquía lograda por los navarros durante la Guerra de Sucesión pudo ser decisiva en el juego de poder

25. Francia había conseguido un privilegio expreso en 1698 para visitar y explotar las montañas del Pirineo (De Pablo, 2020: 35). 
político y el acceso a los asientos. Así, por ejemplo, fidelidad y servicio sirvió con claridad para que, en el gran asiento de provisión de víveres para el ejército, el Estado prefiriese a una compañía española, formada por Goyeneche y Pedro López de Ortega, frente a una compañía de Antonio de Sartine y Onorato de Leotardi, y otros individuos en su mayoría extranjeros (Hernández, 2004: 228) (Ibañez, 1985) (Torres, 2016a: 373-389) 26. Es en este clima de creciente protección real, que se explica cómo Goyeneche aumentó y consolidó su posición en el negocio de la madera. Si en 1699, se hacía con el asiento de Daniel Vanheden, en 1703 lo renovaba, ya solo él como director y sin el socio Vidarte, y en 1717 lo ampliaba. El Estado le ampliaba e imponía nuevas condiciones, especialmente en lo referente a los lugares de entrega de madera, pero también le concedía más privilegios, algunos de ellos no relacionados con la explotación forestal, como licencias comerciales ${ }^{27}$. El resultado de esta escalada es que, en 1717, el mayor contrato de provisión de madera a la Armada estaba en manos de Goyeneche, que aparecía como el principal de una compañía mucho más amplia y sólida, formada por otros hombres de negocios navarros de gran proyección como Juan Bautista Iturralde, Miguel Gastón de Iriarte o Pedro Astrearena (Aquerreta, 2001: 128) ${ }^{28}$. De alguna manera, al resistir en esta turbulenta coyuntura, Goyeneche y sus socios consolidaron definitivamente el control español en la provisión de madera, es decir, una auténtica nacionalización del abastecimiento.

La transición hacia el control español de la explotación de recursos forestales y abastecimiento de madera a la Armada finalmente triunfó, no solo porque ganasen el privilegio y monopolio, sino también porque fue acompañado de sistema más amplio de compensación de beneficios y pérdidas entre diversos tipos de asientos militares. La madera era uno más entre otros asientos igual o más de importantes, como la provisión de víveres al ejército con el marqués de Valdeolmos, de presidios, o el abastecimiento de jarcias a la Armada, ${ }^{29}$. Y todo, a su vez, se compensaba con otros asientos de recaudación de impuestos. El entramado de asientos de provisión y fiscalidad permitía una solidez financiera, crédito y liquidez suficiente para afrontar la multitud de gastos que implicaba la explotación de los recursos forestales.

La propia secretaría de Marina parece que empujó en la dirección de un abastecimiento de maderas exclusivo en manos de españoles. La entrada de José Patiño en 1715 sirvió para mantener la explotación forestal del Pirineo alejada de los extranjeros. La renovación del asiento Goyeneche en 1717 permitía la continuidad de la

26. AHN, Estado, leg. 752.

27. AHN, Estado, leg. 766.

28. AHN, Estado, leg. 766.

29. El asiento de cáñamo y jarcia fue cedido por Juan Francisco de Goyeneche (sobrino de Juan de Goyeneche) en 1723 al también español Juan de Ansalas, otro hombre de negocios español con fuerte actividad en la recaudación de rentas provinciales (Ibáñez, 1985: 338) (Aquerreta, 2001a: 128-130).

Ediciones Universidad de Salamanca / అ@@ Stud. his., H. ${ }^{a}$ mod., 43, n. 1 (2021), pp. 195-226 
explotación de bosques de Aragón y Navarra, más los de Tortosa, y un mayor control de la distribución de la madera a todos los astilleros peninsulares, incluido los del País Vasco. Patiño, además, excluyó expresamente a los franceses del acceso a los bosques del Pirineo catalán ${ }^{30}$. Aprovechó un anterior asiento del catalán Joan Josep Capella, de 1715, para el abastecimiento de madera a las atarazanas barcelonesas (De Pablo, 2020: 54), para extender el sistema de asientos a asentistas catalanes. El estímulo para involucrarse directamente fue el inicio de la construcción en astillero de San Feliú, pero también la lección aprendida en las primeras fases de vida del astillero catalán de la pretensión de que directamente fuese el Estado el que se encargase de la provisión de madera al astillero. La intendencia de Cataluña empezó gestionando la explotación y transporte por sus oficiales, y emitiendo órdenes para exigir la ayuda de vecinos, requisa de medios de transporte..., todo ello pagado por las haciendas locales «sin dispendio alguno por parte del Rey» (De Pablo, 2020: 55). El sistema de administración directa no función y provocó rechazos locales, que animaron a Patiño a contratar con asentistas todas las fases de explotación y transporte de la madera ${ }^{31}$, al tiempo que se prohibía expresamente cualquier exportación de madera hacia el extranjero ${ }^{32}$

La reactivación de la demanda de madera en Cataluña tras la Guerra de Sucesión, para la construcción naval, fortificaciones y diversas expediciones navales a Italia, multiplicó las oportunidades para que más empresarios catalanes se fuesen sumando a la explotación forestal. Esta dinámica, todavía mal conocida (Martí, 2019: 129-158), actuó también en la dirección de apuntalar la nacionalización de la explotación forestal en manos privadas. Todo parece indicar que la coyuntura posterior a la Guerra de Sucesión fue, sin lugar a dudas, un caldo de cultivo para aumentar el interés de inversionistas y empresarios catalanes por los negocios de suministros militares. La continuidad de la concentración de fuerzas militares en el Principado y la organización de expediciones militares hacia Italia debieron ofrecer oportunidades de negocios de provisión que servían para complementar y dar seguridad a su creciente actividad comercial. El nuevo marco fiscal de Cataluña ofrecía enormes posibilidades para transferir rentas directamente a los empresarios, y, de hecho, se capitulaba esta condición ${ }^{33}$. No menos importante era el hecho de

30. En 1724, Patiño prohibió la extracción de maderas de cualquier región de España. (Martínez, 2013: 5).

31. El cambio de idea de Patiño, de administración directa a asiento, se reflejó también en la misma construcción naval, que fue encargada a empresas privadas, primero a Juan Campos y luego a Bernardo Cambí, práctica que se mantuvo en los astilleros del Cantábrico. (Valdez, 2011: 164-165).

32. Esta prohibición se mantuvo en las décadas siguientes. Varios ejemplos para 1739 en (Wing, 2015: 202)

33. En el asiento de 1742 de la compañía Ruesga, se indica expresamente que, el asiento de provisión de madera se hacía con cargo a la recaudación fiscal catalana: «sobre la contribución o Catastro del Principado de Cataluña, que es donde se debe hacer el corte» AGS, Marina, leg. 610.

Ediciones Universidad de Salamanca / అ@@ Stud. his., H. ${ }^{a}$ mod., 43, n. 1 (2021), pp. 195-226 
que para parte de las élites catalanas los contratos de suministros con el Estado eran una ayuda inestimable para construir una retórica de servicios y de fidelidad con Felipe V (Delgado, 2018: 129-154). Esta es una dimensión nada desdeñable en los negocios de abastecimiento militar porque junto a las expectativas de beneficios había también unos cálculos políticos y de proyección social, que no siempre son tan evidentes como sí lo eran en este caso (Graham, 2018: 1-27). De tal manera que tras la Guerra de Sucesión se abrió una coyuntura particular, una auténtica «Hora Catalana», en la que hombres de negocios catalanes aumentaron su participación en los suministros militares, en algún caso incluso con un claro predominio, como ocurrió también con la producción de armas personales o de vestuario ${ }^{34}$.

Esta coyuntura ayudó a impulsar la entrada de asentistas catalanes en la provisión de madera, a poner en valor los recursos forestales del Pirineo catalán y de los bosques de realengo cerca de Tortosa. El resultado fue que durante las décadas de 1730 y 1740 varias empresas catalanas se vieron en condiciones de ser las sucesoras de los asentistas navarros en la provisión de madera. En el abastecimiento de madera para la Armada, a Goyeneche le sucedieron varios asentistas catalanes, como Jaime Planells ${ }^{35}$ y, desde 1742, «Ruesga y Compañía». En 1742, José Campillo contrató con esta empresa el suministro de toda la «arboladura, tablonería, madres, brea negra y alquitrán» que necesitase la Armada, en sus tres Departamentos Marítimos. La compañía estaba formada por un grupo de hombres de negocios principalmente catalanes, con socios aragoneses y madrileños ${ }^{36}$. Su propuesta tuvo que competir con otras empresas, también catalanas, como Antonio Artos, vecino de Barcelona, y, sobre todo, la de Francisco Puget y Agustín Gibert y Xurrich, vecinos de Barcelona, con las que mantuvieron una dura pugna y varios allanamientos y rebajas en los precios y condiciones ${ }^{37}$. Lo interesante de esta competencia es que la opción de provisión de madera para la Armada por súbditos del Monarca seguía consolidándose, y con ello el giro nacionalista.

34. Fueron los casos de los asentistas catalanes Vicente Puyol, Valparda, Florenza, Jaime Planell (Solbes, 2013: 201-234); (Solbes, Dubet, Bertrand y Torres, 2015); (Solbes, 2018: 72-86).

35. AGS, DGT, Inv. 25, leg. 15

36. Gerónimo Ruesga Crespo, vecino de Madrid, Melchor Cortés, vecino de Zaragoza, Carlos Mas y de Areny, vecino de Rialp, corregimiento de Talarn, José Queralt, vecino de Tortosa. Madrid, 30 de junio de 1742. AGS, DGT, Inv. 25, leg. 15.

37. Los Puget y Gibert utilizaban como apoderado para las negociaciones en Madrid a Planells. La propuesta de estos fue también un asiento de arboladura para 12 años (1742-1753). Aunque inicialmente lograron hacerse con la contrata (Buen Retiro, 11-12-1741), Ruesga volvió a hacer nuevas rebajas y se quedó finalmente con el asiento (Madrid, 31-6-1742). AGS, Marina, leg.787. Los bosques de corte previsto en el asiento de Puget y Gibert eran, para los abetes, Espot, Escalot y Escar; para los pinos los bosques de Boumort Carreu, Cellent, Perlas y valle del Lluch; y para los tablones, arbolillos y demás maderas en los anteriores y en Tortosa.

Ediciones Universidad de Salamanca / 요 Stud. his., H. ${ }^{a}$ mod., 43, n. 1 (2021), pp. 195-226 
De tal manera que entre 1680 y 1740 , el estado forestal heredado por los Borbones mantuvo su marco legislativo y fue aumentando progresivamente su control e inspección de los bosques, pero desde el punto de vista de la política de abastecimiento se había producido un importante cambio. Se había paralizado la progresiva entrada de los extranjeros en los bosques peninsulares. De alguna manera, se había cumplido un ideal mercantilista de aumentar la participación de los súbditos de la Monarquía en la gestión de este suministro militar.

\section{EL MONOPOLIO ESTATAL Y EL PRIVILEGIO CONCEDIDO: EL TRIUNFO DEL CONTRACTOR SATE}

Como demostró John T. Wing, todo el esfuerzo legislativo y político desarrollado durante la primera mitad de siglo por el gobierno desembocó en una efectiva «centralización de la gestión forestal» (Wing, 2015: 201), que se plasmó en la Ordenanza de Montes de 1748 y otras leyes posteriores. El objetivo principal de esta legislación forestal era imponer la jurisdicción naval sobre cualquier otra autoridad, y lograr así un monopolio efectivo del Estado sobre la gestión de un suministro estratégico. La pregunta es si esta importante novedad o culminación legislativa alteró la participación del Estado en el abastecimiento de madera. Indirectamente, el propio Wing se hace esta pregunta al concluir: «The major question remained whether these forest ordinances would produce results from which the navy (and the royal court) could derive benefit» (Wing, 2015: 219).

Nadie puede discutir que el Estado aumentó de forma notable su conocimiento sobre el potencial de explotación de recursos forestales en toda la Monarquía, especialmente en la Península desde la década de 1730. Del mismo modo que está claro que mejoró de forma extraordinaria su capacidad administrativa y judicial para intervenir sobre las plantaciones, conservación y corte de los árboles peninsulares y ultramarinos. Lo que ya no está tan claro, o al menos no parece que haya suscitado el mismo interés entre los investigadores, es si todas esas herramientas de acción política fueron dirigidas a conseguir una intervención directa sobre la explotación y provisión forestal. Es decir, si todo este potencial de conocimiento y capacidad gubernamental se tradujo en un cambio en la gestión del abastecimiento. O, dicho de otro modo, si el Estado español quiso o pudo establecer una gestión directa sobre la provisión de madera que había logrado monopolizar. Simplemente plantear el problema es ir directamente a la cuestión que siempre está presente en las reformas borbónicas: la adecuación entre los objetivos de los proyectos y la realidad de la política. En este sentido, quizás debería subrayarse la significativa coincidencia entre la Ordenanza de 1748 y el mayor contrato de suministro de madera de todo el siglo, en el que se contrató con el empresario de Cantabria, Juan Isla, la provisión de madera suficiente para construir más de 50 navíos (Maiso, 1990: 236; Merino,

Ediciones Universidad de Salamanca / అ@@ Stud. his., H. ${ }^{a}$ mod., 43, n. 1 (2021), pp. 195-226 
1981: 192-193; Valdez, 2011; 2018: 105-125). Según esto, cabría también interpretar el triunfo del Estado forestal, al imponer la jurisdicción de marina sobre los bosques y el monopolio del Estado sobre este recurso, como una manera de garantizar al asentista unas condiciones privilegiadas de acceso a la madera monopolizada por el Estado. En la práctica, el Estado había logrado extender su autoridad sobre los bosques e intereses locales, para luego compartir esa autoridad con agentes no estatales. Las intenciones de este traspaso de autoridad pueden ser interpretables, desde la imposibilidad del Estado de realizar esa gestión directa hasta valorarse como una acción política del Estado con el fin último de que los asentistas pudiesen ejercer con más eficacia su actividad (Hamish, 2002: 381-401; Hamish, 2009: 319). Lo que parece evidente es que se entraba en una fase en la que el monopolio y privilegio se convertían en herramientas de acción política del Estado, con el fin último de lograr garantizar el abastecimiento militar, auténtica prioridad del Estado (Torres, 2016; Sánchez, 2020: 1-12).

De acuerdo a esta interpretación, el triunfo del estado forestal fue, en realidad, el triunfo del Contractor State, es decir, del Estado que obtenía sus recursos mediante su contratación privada. El reto no era hacer un contrato sino hacerlo con garantías para que ambas partes cumpliesen. A cambio de que el Estado dejase toda la gestión forestal en manos de los asentistas, éstos recibirían una serie de privilegios y protecciones del Estado. Esto es importante porque constituye la base de una colaboración y el instrumento imprescindible para avanzar en la dirección de beneficio para ambos: más seguridad para los contratistas y más autoridad para el Estado (Leonor, 2009: 219-261; Torres y Angulo, 2021). Los asentistas podían actuar ante los pueblos y particulares propietarios de bosques como representantes del rey, en virtud del contrato firmado. Esta condición de «servidores del rey», daba unas ventajas valiosas a los contratistas. El Estado les garantizaba un monopolio de corte de madera. Se les permitía entrar en los bosques de cualquier jurisdicción, y las maderas cortadas, incluidas las de propietarios particulares o de pueblos, se pagaba el precio estipulado, no el de mercado. Para el transporte, una de las cuestiones que más conflictividad provocaba, los asentistas contaban también con el apoyo del Estado. Los contratistas podían exigir directamente a las justicias cercanas a los bosques y ríos que los pueblos por donde pasaba la extracción de madera les facilitasen los trabajadores, carretas y bestias de tiro, y ellos solo se encargarían de contratar a los conductores. De cuenta de los asentistas era también el transporte marítimo hasta los arsenales, incluida su entrega en los astilleros, diques o parajes donde se decidiese. Aquí también tendría la protección estatal, puesto que los contratistas podían embargar los buques de transporte que necesitasen, de la nacionalidad que fuesen. Además, en principio, no pagarían impuestos por la madera entregada en los puertos y, además, contarían con una cantidad de dinero adelantado por la Real Hacienda, con cargo a lo que el Estado finalmente pagase. El Estado les concedía un anticipo que servía a los contratistas para empezar a pagar la multitud de pequeños

Ediciones Universidad de Salamanca / 요 Stud. his., H. ${ }^{a}$ mod., 43, n. 1 (2021), pp. 195-226 
desembolsos a cientos de trabajadores en el bosque, ríos y transportes marítimos. La concesión de todos estos privilegios y condiciones favorables a los asentistas fue una realidad práctica, que no fue alterada por la Ordenanza de 1748 ni la nueva legislación forestal. Era el marco esencial en el que se mantenía las relaciones entre Estado y asentista, pese a que en esos mismos años arreciasen las críticas y oposición a los asentistas que los escritores y políticos de la época seguían repitiendo, y que luego los historiadores han interpretado como un frontal rechazo a esta vía de conseguir los suministros militares (Fernández, 1977: 51-81) (Ibáñez, 1985). El mantenimiento de ese marco de relaciones pese al cambio legislativo podría interpretarse más como una colusión de intereses entre Estado y asentista que un enfrentamiento entre ellos. Todo parece apuntar hacia que las aparentes esferas de lo "público» y lo "privado» se diluían en un marco de relaciones presidido por las claves de la realidad histórica de ese momento, en las que lo importante era que la autoridad del Rey no fuese cuestionada por nada ni por nadie, y que la madera requerida por sus fuerzas armadas fuese entregada al Estado, con regularidad y tal y como el Estado lo demandaba (Allen, 2017: 1-27).

El Estado español había conseguido con la normativa forestal de 1748 la autoridad necesaria para hacer cumplir el uso político de los privilegios y la provisión mediante contratos. Y este logro significa una evolución. Las diferencias entre las posibilidades de actuación entre Juan de Goyeneche y Juan de Isla fueron enormes. Mientras el empresario Isla actuaba como un auténtico «servidor del rey», respaldado por su administración, justicia y oficiales, con capacidades plenas para superponerse a cualquier particular, comunidad, autoridad y jurisdicción local, el navarro Juan de Goyeneche, que aparentemente tenía privilegios similares, en la práctica tuvo serios problemas para gestionar la corta y transporte de madera en Navarra, precisamente porque su monopolio y privilegios no estaban por encima de la legislación foral navarra. Cualquier valle o municipio navarro, pero también un noble o villa, podía cuestionar el privilegio del asentista Goyeneche, hasta el punto de preferir vender madera a otros compradores antes que al privilegiado Goyeneche (Aquerreta, 2001a: $103)^{38}$. Entre Isla y Goyeneche, no solo el marco normativo forestal se había definido mejor en beneficio del Estado, también se había modificado notablemente la capacidad de gestión de ambos, Estado y empresarios, y eso es el auténtico triunfo del Contractor State.

$\mathrm{Al}$ aumentar la autoridad en materia forestal, el Estado podía iniciar relaciones más complejas con los asentistas de la provisión de madera. Es un tema todavía a profundizar, pero todo apunta a que el Estado incorporó a estos asentistas en su propia estructura de gestión gubernamental, lo que constituye uno de los ejes del Estado fiscal militar español (Torres, 2013). Los asentistas podían llegar a ser un

38. Ya vimos que algo similar le ocurrió a Bastida.

Ediciones Universidad de Salamanca / @@ Stud. his., H. ${ }^{a}$ mod., 43, n. 1 (2021), pp. 195-226 
más eficaz instrumento de acción política estatal. Un buen ejemplo lo encontramos cuando el Estado intentó paliar el aumento del precio del abastecimiento de madera de Cantabria en la década de 1760 con la apertura de la provisión desde Navarra. Los oficiales de la Armada conocían el potencial de los bosques navarros y que era una solución viable a la creciente demanda de madera del arsenal de Ferrol, pero para explotar todo este potencial había que resolver dos problemas. Por un lado, la corta y arrastre hasta algún puerto del Cantábrico. Componer caminos y habilitar el paso de almadías podía elevar de forma cuantiosa cualquier intento de explotación. Por otro lado, había que garantizar el transporte marítimo de la madera hasta el Ferrol. La Real Hacienda había vivido los numerosos problemas que tuvo Juan Isla para conseguir buques en los que transportar la madera del Cantábrico, precisamente cuando el Estado le añadió e impuso a sus obligaciones como asentista contratado para Guarnizo el asumir también los fletes y la búsqueda de buques hasta Galicia (Torres, 2021). Con todo, lo que hacía especialmente complejo el abastecimiento desde Navarra hasta Ferrol era la dificultad para el Estado y para Isla o cualquier asentista para coordinar la gestión de ambos problemas: el corte y arrastre en Navarra con la distribución regular por mar de la madera. La solución que encontró el Estado fue acudir a la Compañía Guipuzcoana de Caracas, y proponerle una comisión ${ }^{39}$. En 1766, según los propios directores de la Compañía, el Estado se aproximó a ellos «en términos de pura confianza» para que se encargasen de esta provisión por cuatro años ${ }^{40}$.

La gestión de este abastecimiento era una compleja operación empresarial, que exigía una extraordinaria capacidad de organización de numerosas tareas e individuos. La Compañía lo abordó mediante una multiplicación de contratos y subcontratos con otros asentistas, comerciantes, pueblos y particulares, en Navarra pero también en otros puertos ${ }^{41}$. Entre la multitud de fases a armonizar, destacaba la extraordinaria dificultad para financiar todos los convenios y contratos que la Compañía tenía que acomodar. La mayor parte de la actividad en la explotación forestal exigía, sobre todo, liquidez, es decir, ir pagando puntualmente sueldos, compra de víveres, herramientas o fletes. Se requería una extraordinaria flexibilidad a la hora de colocar dinero en una geografía extendida. Precisamente esta flexibilidad en los pagos sobre el terreno era algo que marcaba la diferencia respecto a las limitaciones que tendría una gestión directa por el Estado, por la limitada implantación

39. AGN, Reino, Montes, leg. 1, n. ${ }^{\circ} 49,1766$.

40. Juan Bautista Goizueta y Vicente Rodríguez de Rivas a Julián de Arriaga, Madrid 29-XI-1771, AGS, Marina, leg. 649.

41. La lista de individuos y corporaciones contratos es extensa. Encontramos desde el asentista en Fuenterrabía, Manuel de Zubiría, a María Fermina de Ciriza, vecina de Pamplona, a la que se le compraron 556 árboles, Madrid, 29-11-1771, AGS, Marina, leg. 349.

Ediciones Universidad de Salamanca / @®@@ Stud. his., H. ${ }^{a}$ mod., 43, n. 1 (2021), pp. 195-226 
territorial de las tesorerías de la Real Hacienda, tanto del ejército como de rentas ${ }^{42}$. La Compañía, en cambio, fue capaz de ofrecer en cualquier punto de la geografía de este asiento crédito y liquidez, y lograr así la flexibilidad imprescindible para ordenar la gestión de la comisión del Estado. El resultado pudo ser positivo. Todo apunta a que la Compañía atendió con éxito el encargo del Estado, al menos si lo valoramos por la regularidad de las entregas y por el escaso porcentaje de madera rechazada por algún defecto al ser entregada en Ferrol, solo el 5,4 por ciento del total ${ }^{43}$. El Estado no dudó en extender el contrato hasta 1782, lo que supuso al Estado algo más de 19 millones de reales. Lo más interesante de esta imbricación entre Estado y Compañía es que sugiere que el abastecimiento de madera aparecía dentro de un juego más amplio de intercambio de servicios. Así, por ejemplo, para pagar el abastecimiento de madera de Navarra, el Estado concedió a la Compañía permiso para no abonar los derechos comerciales que debía pagar durante esos años en las aduanas peninsulares por el tráfico marítimo de sus buques. Su importe se descontaría posteriormente del coste que hubiese tenido todo el abastecimiento de madera ${ }^{44}$. Además, el Estado añadió como pago por la madera que iba recibiendo de la Compañía el coste, no pagado, de otros servicios de la misma Compañía al Estado: como el encargo de transportar al regimiento de Granada, «por lo suministrado a las Misiones de Capuchinos», «lo suplido en la comisión de la pesca de Cumaná»... ${ }^{45}$. De tal manera, que el suministro de madera formaba parte de un sistema más amplio de acción política.

Esta imbricación entre Estado y asentista podía haber dado lugar a una evolución hacia un rotundo monopolio de abastecimiento de madera para las fuerzas armadas. Es decir, que solo un asentista o una compañía se encargase de todo el suministro de madera a los arsenales españoles. Con el precedente de monopolio de facto de Juan Isla, cabría pensar que el camino ya estaba iniciado. La hipótesis no es descabellada puesto que la experiencia en otros tipos de suministros militares fue precisamente en esa dirección (Torres, 2016b). El Estado borbónico encontró más eficaz y seguro para obtener sus pertrechos militares reducir el número de intermediarios en las gestiones. La idea era que el gobierno limitaba su negociación a un único

42. Ni siquiera un asentista era garantía de pago a los propietarios o empleados. Véase, los impagos dejados por los asentistas Lorenzo Paniagua y Carlos Ignacio de Gallart en los montes catalanes en 1748, (Martínez, 2015b: 1212).

43. En los cuatro años de 1766 a finales de 1770 justificó la entrega de 152.827 codos cúbicos (16.346 árboles), de los cuales solo se habían rechazados por defectuosos en Ferrol 8.400 codos. AGS, Marina, leg. 349.

44. Entre 1766 y 1770 un total de 42 buques de la Compañía adeudaron derechos reales en las aduanas de San Sebastián y Pasajes por comercio con Caracas y Maracaibo por valor de 8.460.570, y en la de Cádiz, 9 navíos, por valor de 4.742.487 rsv. AGS, Marina, leg. 347.

45. AGS, Marina, leg. 349.

Ediciones Universidad de Salamanca / అ@@ Stud. his., H. ${ }^{a}$ mod., 43, n. 1 (2021), pp. 195-226 
empresario o compañía, con lo que podía dirigir sus demandas con más rapidez, exigir cambios y canalizar información confidencial, como era toda la que suponía hacer público que se aumentaba el gasto militar. A cambio, el Estado le ofrecía al asentista monopolista un marco de seguridad para sus negocios, fortaleciéndolo con más privilegios, preferencias y apoyos financieros. De tal manera que la posibilidad existía, y que en otras áreas de suministros militares ya era una realidad. Que fuese una actividad compleja como la explotación de madera no parece que fuera un obstáculo insalvable para lograr ese monopolio de facto. De hecho, la experiencia en la complicada gestión de la provisión de víveres, en la que se impuso un monopolio, demuestra que sí se podía lograr. Pensemos que, en el caso del abastecimiento de víveres, se pudieron resolver problemas logísticos tan difíciles como la preparación semanal de millones de raciones, con miles de puntos de entrega, muchos de los cuales, en continuo movimiento, y con una variedad enorme de productos, que en el caso de la Armada exigía reunir y preparar más de 17 productos. En cambio, en la explotación de la madera no se logró un monopolio efectivo del abastecimiento de madera. Lo que encontramos durante toda la segunda mitad de siglo es una convivencia de multitud de asentistas. Incluso cuando la Compañía Guipuzcoana de Caracas estuvo al cargo de la mayor parte de la provisión de madera peninsular para Ferrol, la madera seguía llegando al arsenal gallego también desde los bosques cantábricos y pirenaicos de la mano de otros asentistas, algunos importantes como Juan González Pola, Francisco Cayetano Iglesias o la viuda de Saint Aulary ${ }^{46}$.

Que no se lograra un monopolio en el suministro de madera no quiere decir que no se intentase. De hecho, el Estado lo intentó e incluso llegó a conseguir temporalmente ese monopolio en lo relacionado con la importación de maderas extranjeras. La experiencia de hacer encargos de madera y de todo tipo de pertrechos navales a comerciantes extranjeros había sido una práctica habitual, tanto de los Austrias como de los Borbones. La novedad desde mediados del siglo XVIII fue que el Estado intentó limitar el número de esos contratos. Esta estrategia se pudo realizar porque la secretaría de Marina era la única que gestionaba estos contratos y sus presupuestos navales los únicos que lo pagaban (Torres, 2018a: 53-76). La concentración de la gestión administrativa de los contratos de importación de madera favoreció, además, la posibilidad de imponer una política de nacionalización de los asentistas, incluso en un sector de negocios como este, tan escurridizo para los comerciantes españoles.

La política de implementar una concentración del suministro de madera importada y nacionalización comenzó a ser efectiva con la llegada de Carlos III. Buena parte de la distribución de maderas por la costa peninsular y entre astilleros había

46. Datos sobre sus entregas en Ferrol durante la década de 1770 en AGS, Marina, leg.347. Sobre las actividades de la compañía de Santa Aulary en la provisión de pertrechos a Ferrol (Torres, 2016b).

Ediciones Universidad de Salamanca / అ@@ Stud. his., H. ${ }^{a}$ mod., 43, n. 1 (2021), pp. 195-226 
quedado en manos una compañía portuguesa, Gil de Meester, la solución que finalmente se encontró a la incapacidad de Juan de Isla de afrontar la imposición de transportar la madera del Cantábrico a Ferrol (Torres, 2021). La compañía era formalmente portuguesa, pero estaba formada por los hermanos holandeses Daniel y Juan Gil de Meester, vecinos de Lisboa, de origen judío y con importantes negocios en Brasil y Holanda. Aunque era extranjeros, estos hombres de negocios eran bien conocidos de la Real Hacienda española, puesto que había conseguido en 1743 el estratégico suministro de tabaco de Brasil para la Renta del Tabaco española (Torres, 2006: 721-760). Precisamente el control de la distribución de tabaco a lo largo de las factorías de la costa española le dio la posibilidad de movilizar un activo transporte de cabotaje, y convertir esta capacidad en una oportunidad para ofrecer servicios de transporte de madera. El resultado fue que la compañía fue la más activa en el transporte de maderas entre el Cantábrico y Ferrol desde $1747^{47}$, implicación que en los años siguientes extendió a la conducción también a los arsenales de Cádiz y Cartagen $a^{48}$. Juan Isla no pudo mantener esta competencia, y de nada sirvieron sus quejas y apelaciones a un mercantilismo compartido con el Estado, para reclamar preferencia como única solución para que «el dinero que se iban a llevar los holandeses se quedase en el reino» (Maiso, 1990: 297). Para los secretarios de Marina era más útil contar con un sistema de transporte para distribuir con rapidez y seguridad la madera por toda la costa peninsular, así como entre arsenales. Lo importante de esta batalla es que mejoró la posición y acceso de los Gil de Meester en la secretaría de Marina, y en 1752 el Estado aceptó su propuesta para contratar por ocho años la provisión de pino para arboladuras a los tres departamentos, procedente del Báltico, en concreto de Riga ${ }^{49}$. La compañía había superado a su gran competidor, Juan Isla, y sobrevivido a la caída del marqués de la Ensenada, ofreciendo lo que la secretaría de Marina quería: seguridad en la provisión de madera desde un mercado lejano. A cambio, el Estado le concedía la exclusividad en el monopolio de importación hasta 1759. Parece ser que el Estado tomaba esa decisión tras haber fracasado en realizar un acuerdo similar por la vía diplomática. Ahora surgía una oportunidad con alguien, que, si bien era extranjero, tenía suficientes negocios con la Real hacienda española como para ofrecer fianzas suficientes ${ }^{50}$. El Estado aceptó conceder el monopolio

47. Eugenio de Mena, Madrid, 2 de diciembre de 1748, AGS, Marina, leg. 787.

48. Eugenio de Mena, Madrid, 2 de diciembre de 1748, AGS, Marina, leg. 787.

49. Eugenio de Mena, Madrid, 2 de febrero de 1751, AGS, Marina, leg. 787. La ampliación a Cádiz, Julián de Arriaga, 8-8-1752, AGS, Marina, leg. 787.

50. Se había intentado ajustar el abastecimiento directamente en aquel mercado utilizando a los representantes diplomáticos en la zona como el conde Bena, que estaba en la Dieta, Varsovia, para que volviese por Danzig y ajustase el abastecimiento de arboladuras del norte para los tres arsenales. Madrid, 10 de septiembre de 1748, AGS, Marina, leg. 315.

Ediciones Universidad de Salamanca / @®@@ Stud. his., H. ${ }^{a}$ mod., 43, n. 1 (2021), pp. 195-226 
y, lo que es significativo, cumplió su parte, al rechazar ofrecimientos similares de hombres de negocios del Báltico ${ }^{51}$.

Abrir el mercado de la importación de madera a la competencia era algo que el Estado consideraba arriesgado, y la experiencia con los contratos para traer madera de Italia a principio de la década de 1760 se lo confirmaron ${ }^{52}$. Pero tampoco el Estado borbónico quería dejar en manos de extranjeros este monopolio. Consecuentemente, se maniobró para que el monopolio concedido a Gil de Meester pasase a alguna casa comercial española. Es decir, intentar mantener el monopolio de la importación de maderas, pero en manos nacionales. Para lograrlo, el marqués de Esquilache organizó una subasta, algo verdaderamente inusual para el abastecimiento de pertrechos navales importados. Lo que hizo que fuese verdaderamente excepcional esta subasta fueron los extraordinarios esfuerzos desplegados por las autoridades para que acudiesen y pujasen en el concurso importantes casas de negocios españolas, como Miguel de Soto, conde de Clonard, y Simón de Aragorri, marqués de Iranda. En una sorprendente sucesión de pujas a la baja, tanto por la cuantía de las ofertas como el número y acumulación, los Gil de Meester perdieron en 1760 el monopolio de importación en favor de Aragorri ${ }^{53}$. En adelante, toda la provisión de arboladura del «Norte», del Báltico, estaría a cargo de una compañía española. Este transcendental cambio en la nacionalización del asentista se mantuvo en los años siguientes, cuando a Aragorri en 1772 le sucedió el conde de Clonard, en cabeza de Felipe Chone, ahora ya sin un procedimiento de subasta tan aparatoso. La apuesta del Estado por este monopolio nacional de importación de maderas funcionó, puesto que lograron la vieja aspiración de deshacerse de la intermediación de los holandeses para acceder al Báltico, e incluso avanzaron en la presencia española en aquel complejo mercado, puesto que los asentistas españoles llegaron a contar con una casa abierta en San Petersburgo para comprar directamente la madera para la Armada ${ }^{54}$.

El modelo de monopolio con asentistas nacionales y fuertemente apoyado por el Estado en la importación de maderas del Báltico siguió funcionando en los años siguiente, pero la guerra de Independencia Norteamérica provocó la paralización de este comercio y la ruina de los asentistas españoles que operaban

51. En 1753, la casa Juan Felipe Schulz, hombres de negocios de Danzig propuso entrar en el suministro desde el Báltico, Luis Perrot al marqués de la Ensenada, Danzig, 27 de junio de 175, AGS, Marina, leg. 322.

52. Aquí el Estado firmó contratos con el genovés Joseph Marcerano y con la compañía también genovesa Monticelli para llevar madera de la Romaña y Toscana a Cartagena, AGMAB, Contrata de Joseph Marcenaro, Arsenales, Maderas, Leg. 3762 y AGMAB, Advertencias de Juan Bautista Monticcelli, Arsenales, Maderas, Leg. 3762. Sobre estos asientos véase también, AGS, Marina, leg. 605.

53. Marqués de Esquilache, San Ildefonso 5-9-1760, AGS, DGT, Inv. 25, leg. 15.

54. Conde de Clonard a Múzquiz, Cádiz 2-9-1774, AGS, SSH, leg. 50. 
en aquel mercado ${ }^{55}$. Los esfuerzos del Estado por sostener a sus sucesores, Pedro Normande y Antonio Colombí en San Petersburgo ${ }^{56}$, no sirvieron para restaurar el crédito en aquel mercado. Ni siquiera, perdonándoles deudas y liberándolos del pago de impuestos, porque reconocía el secretario de Marina «no es el momento de entibiarlos» ${ }^{57}$. De nuevo, buscó una solución concediendo el monopolio, pero esta vez al recién creado Banco de San Carlos ${ }^{58}$. Los directores del Banco se vieron obligados a aceptar esta imposición, pero eran plenamente conscientes de que, de todas las provisiones militares, el asiento de arboladura y tablazón «es tal vez el más engorroso de todos» ${ }^{59}$. El Banco no quiso en ningún momento atender este servicio, lo aceptó porque era el único medio que tenía su fundador Francisco Cabarrús, de conseguir su verdadero objetivo, que era el control y monopolio de la exportación de plata. La gestión por el Banco resultó, efectivamente, complicada y, de nuevo, el Estado intentó sostener al Banco, permitiéndole no pagar impuestos y ordenándolo a las autoridades de los Departamentos Marítimos que «no se estrecha al Banco como a los particulares» ${ }^{60}$. Para salir de este atolladero político-económico, el Banco propuso un cambio radical de las condiciones del contrato de suministro de madera del Báltico, imponiendo al Estado un fuerte incremento de precio de la madera, de media el 52 \% y compensaciones económicas por si había cambio en los impuestos pagados en el Báltico ${ }^{61}$. Con este nuevo contrato, la Junta del Banco no buscaba una mayor implicación en el negocio de la importación de maderas sino una base económica mucho más sólida para hacer viable lo que era su verdadero objetivo: salir lo antes posible de esta compleja actividad. Sus verdaderas intenciones quedaron en evidencia rápidamente, y en pocos meses paso a subarrendar el asiento de madera a otros comerciantes, españoles y extranjeros, y desde 1791 quedó en manos del sueco Juan Jacobo Gahn ${ }^{62}$. Es decir, se acababa con cualquier intención política del Estado de mantener un monopolio, y menos en manos de nacionales.

La importancia del monopolio de importación logrado temporalmente es aún más destacada si la comparamos con la dificultad que existió para establecer tal provisión exclusiva para el abastecimiento con maderas peninsulares, dejamos por ahora el caso de las maderas americanas. Al contrario de lo ocurrido en las

55. Floridablanca a Múzquiz, 20-9-1781, AGS, SSH, leg. 10.

56. Flor a Lerena, Madrid, AGS, SSH, leg. 10

57. Castejón a Múzquiz, 16-2-1780, AGS, SSH, leg. 51.

58. AHN, Estado, leg. 3219, n. 24.

59. Juntas Generales del Banco de San Carlos, JGBS, Segunda, tomo II, 20-XII-1783, Libro 2780 , p. 9.

60. Mayo 1785, AGMAB, Arsenales, Maderas, leg. 3770.

61. Biblioteca Central Ministerio de Marina, Libro 16531, Antonio Valdés, Palacio, 13-12-1786.

62. JGBS, Novena a, tomo II, 20-9-1790, Libro 22692, p. 237.

Ediciones Universidad de Salamanca / 요 Stud. his., H. ${ }^{a}$ mod., 43, n. 1 (2021), pp. 195-226 
importaciones, desde mediados de siglo la provisión de maderas de áreas forestales de la Península se realizó mediante cientos de contratos con asentistas particulares. Aunque es un tema apenas estudiado, se produjo una auténtica «atomización» de los contratos de provisión de madera. En todas las áreas forestales encontramos la misma proliferación de asientos de maderas, en los que prima un horizonte empresarial local, de abastecimiento al arsenal más cercano. La evolución en el número y geografía de estos contratos tiene que ver más con la intensidad de la demanda para la construcción naval. Así, el aumento de la actividad constructiva en Ferrol animó a más contratos asturianos, guipuzcoanos y navarros, y lo mismo en Cartagena, con la activación de asientos en Sierra del Segura, áreas forestales de Valencia, Cuenca, Cataluña y Navarra. Lo interesante de esta evolución es plantear por qué se fue hacia la atomización en lugar de un monopolio.

Una posible explicación tiene que ver con los cambios sufridos en la propia estructura administrativa y de gestión forestal de la Armada. Desde la década de 1760, la secretaría de Marina vivió una lucha interna por conceder más o menos autonomía institucional a los Departamentos Marítimos, en concreto a las autoridades de los arsenales. Aunque pueda parecer que no tiene nada que ver con la concesión y control de los asientos por el Estado, todo empieza a apuntar a que fue un elemento esencial para comprender la política de suministros de madera. Los Departamentos Marítimos fueron ganando autonomía para contratar directamente los contratos de suministro, algo que quedó sancionado en las ordenanzas de arsenales de 1772 y 1776 (Torres, 2018b: 329-435) (Torres, 2018a: 53-76). Las Juntas Departamentales pasaron a tener un papel activo en la promoción de asientos para explotar y gestionar los recursos forestales de sus jurisdicciones. Las respectivas capitales departamentales se convirtieron en los principales puntos desde y donde se gestionaba las nuevas contrataciones de asientos de provisión de madera, y los propios oficiales de marina enviados a inspeccionar los bosques de sus respectivas jurisdicciones se convertían en un canal de información a los pueblos y vecinos sobre las demandas de maderas y las posibilidades de contratar cualquiera de las fases de la provisión: corte, acarreo, transporte fluvial, marítimo. No hacía falta que se encontrase a grandes hombres de negocios, sino más bien todo lo contrario, modestos vecinos que copiaban y rivalizaban entre sí ante la oportunidad de convertirse en «servidores del rey».

La espiral de atomización quedó más unida a la creciente autonomía departamental al ir todo este proceso acompañado de una definitiva autogestión de las Juntas Departamentales de los presupuestos navales. En adelante, eran las respectivas Juntas las que distribuían sus fondos para contratar sus suministros, no la secretaría de Marina. Esto explicaría la progresiva reducción de la intervención de la secretaría de Marina en la gestión de los nuevos contratos. De hecho, fue una limitación en la capacidad de financiación de Ferrol lo que permitió que la secretaría de Marina mantuviese un papel activo en la importación de maderas. Ferrol

Ediciones Universidad de Salamanca / అ@@ Stud. his., H. ${ }^{a}$ mod., 43, n. 1 (2021), pp. 195-226 
era el departamento Marítimo con peores condiciones de conseguir financiación extraordinaria y dependía exclusivamente de su presupuesto. Mientras en Cádiz y Cartagena, y aún mejor en la Habana, se podía lograr atender la flexibilidad que requería el gasto militar con el acceso a otras fuentes, en Ferrol prácticamente tenía su gasto limitado al presupuesto solicitado y autorizado por la Tesorería General. Para resolver el problema de rigidez del arsenal ferrolano se decidió que todas las maderas importadas fuesen con cargo directamente a la Tesorería General, y no al presupuesto de Ferrol, como era lo ordenado para el resto de arsenales. El resultado es que la madera importada, en un elevado porcentaje para Ferrol, no era contratada por Ferrol, sino por Madrid. Es decir, era la secretaría de Marina quien se encargaba directamente de su contratación y la Tesorería General de su pago, también en Madrid o donde fuese, aunque luego descontara parte del gasto a la consignación de Ferrol. Al final, la provisión de maderas importadas fue un campo de acción del secretario de Marina. Pese al elevado consumo de este tipo de maderas en Ferrol, las limitaciones financieras de esa plaza impidieron que se fragmentara este suministro y que se pudiese desarrollar una política de monopolio. Todo lo contrario que ocurría con las maderas peninsulares, que eran contratadas en los Departamentos, pero ya no eran pagadas en Madrid sino en los respectivos arsenales (Torres, 2018a; 2018b).

El resultado de todo este proceso fue una rápida multiplicación y regionalización de los asientos de provisión de maderas por toda la Península. Lo interesante de esta atomización de contratos de abastecimiento de maderas peninsulares es que la iniciativa ahora venía de abajo arriba. Eran los propios vecinos y pueblos los que ofrecían los asientos de provisión. En las propuestas había soluciones conocidas, como la de Arnaldo Rován, para llevar maderas al arsenal de Cartagena desde bosque de Aragón y Cataluña ${ }^{63}$, pero también se proponía la explotación de zonas menos habituales, como Cuenca, con los asientos de vecinos de Valencia como Vicente Fornells, Francisco Gil, Ramón Aldurriaga o Mariano Palles ${ }^{64}$, o la sierra del Segura (López, 2018: 127-168) (Ruiz, 2018). Lo interesante de estos asientos es que tenían un efecto de imitación en la zona. Tras cada asiento podían aparecer más asentistas, más propuestas. Así, por ejemplo, cuando acabó el contrato de Arnaldo Rován en 1775, en la subasta pública posterior, a la propuesta de renovación del propio Rován se sumaron otras cuatro proposiciones: de la compañía del asentista Roque Bieu, otra de Antonio Coste, una de un noble, el barón de Blancaflor, junto a Francisco Sangenís y su hermano el abad de Vitoria, y otra más de la compañía

63. AGMAB, Arsenales, Madera, leg.3767. Fue similar la del asentista Joaquín Jovellar para un uso intenso del pirineo aragonés y la vía de Tortosa, 1766. AGMAB, Montes, Leg. CG.947. AGS, Marina, leg. 574.

64. Asientos desde finales de la década de 1760, AGS, Marina, leg. 605. AGMAB, Arsenales, Maderas, leg. 3762, AGS, Marina, leg. 580. 
de Juan Ludeña, que resultó finalmente ganadora ${ }^{65}$. Las propuestas no solo ponían en explotación más áreas forestales sino incluso ofrecían soluciones a algunos de los problemas más habituales como era la extracción de la madera. Así, en la sierra del Segura, tras numerosos estudios e informes sobre el potencial maderero y la dificultad para construir carreteras y habilitar ríos, el asentista Manuel Bernia, ofreció en 1784 un asiento a la Junta Departamental de Cartagena para resolverlo y extraer pino hasta el arsenal cartagenero (López, 2018: 144-146). Y lo mismo hizo el navarro Pedro Vicente Gambra con el enorme potencial forestal del valle del Roncal (Aragón y Riezu, 2020) (Riezu, 2019). Gambra, además, ofrece un excelente ejemplo de cómo se podía lograr movilizar recursos locales e iniciar un ascenso en el horizonte empresarial. Aunque es un tema todavía poco estudiado, todo apunta a que había margen para explotar los recursos forestales y hacerlo con más flexibilidad y variedad de fórmulas. Si no se alcanzó un monopolio en el abastecimiento de maderas peninsulares durante el último tercio del siglo XVIII, quizás fue porque había un potencial de asentistas locales y regionales, que ahora, con el marco de estabilidad y privilegio que ofrecía el Contractor State, podía activarse.

\section{CONCLUSIONES}

El Estado Forestal fue el producto de una necesidad: el control judicial y administrativo de un recurso militar imprescindible para el Estado como era la madera para la construcción naval. El gran obstáculo a resolver por ese Estado Forestal era superar la multitud de jurisdicciones y trabas fiscales y comerciales que impedían el uso y movilidad de maderas. Tras muchos avances y perfeccionamientos, se ha considerado que el Estado Forestal logró triunfar. El artículo plantea el verdadero significado de ese triunfo, es decir, si conforme el Estado lograba el monopolio sobre el uso de la madera cambiaba también el sistema de provisión de madera. El artículo ha demostrado que la continuidad del Estado Forestal reclamada por la historiografía y su momento triunfal con la Ordenanza de 1748 no son razones suficientes para comprender la evolución en el uso y provisión de maderas. El análisis de la política de suministros desde finales del siglo XVII muestra que el Estado utilizó su progresivo incremento de autoridad para mejorar las condiciones de explotación de los asentistas. El Contractor State administró entonces su capacidad de dar privilegios y monopolios y su indiscutible autoridad superior para lograr cambios en su política de abastecimiento, algunos tan importantes como la imposición de una nacionalización en los asentistas madera. La madera fue más que nunca, la madera del rey, pero la explotación fue también, más que nunca, con la colaboración y beneficio de sus súbditos.

65. AGMAB, Arsenales, Maderas, leg. 3767.

Ediciones Universidad de Salamanca / @@ Stud. his., H. ${ }^{a}$ mod., 43, n. 1 (2021), pp. 195-226 
RAFAEL TORRES-SÁNCHEZ

¿EN QUÉ CONSISTIÓ EL TRIUNFO DEL ESTADO FORESTAL? CONTRACTOR STATE

Y LOS ASENTISTAS DE MADERA DEL SIGLO XVIII

\section{BIBLIOGRAFÍA}

Allen, D. W. (2017). The Lesser of Two Weevils»: British victualling organization in the long eighteenth Century. European Review of Economic History, 1-27.

Andújar Castillo, F. (2007). Juan de Goyeneche: financiero, tesorero de la reina y mediador en la venta de cargos. En A. González (coord.), Navarros en la Monarquía española en el siglo XVIII (pp. 62-88). Pamplona: EUNSA.

Aquerreta, S. (2001a). Negocios y finanzas en el siglo XVIII: la familia Goyeneche. Pamplona: EUNSA.

Aquerreta, S. (2001b). Financiar la Guerra de Sucesión: Asentistas y compañías al servicio de Felipe V. En P. Castañeda y E. Gómez (coords.), La Guerra de Sucesión en España y América (pp. 569-582). Sevilla: Deimos.

Aragón Ruano, Á. (2011). La historiografía forestal sobre época moderna en el panorama internacional, español y vasco: una revisión bibliográfica. Vasconia, 37, 117-140.

Aragón Ruano, Á. (2017). Mar de árboles, vorágine de jurisdicciones: La complicada relación entre la Real Armada Española y los bosques del pirineo occidental peninsular en el siglo XVIII. En R. Varela y K. Trápaga (eds.), Árvores, barcos e bomens na Península Ibérica (séculos XVI-XVIII) (pp. 41-54). Zaragoza: Libros Pórtico.

Aragón Ruano, Á. (2019b). Ríos de madera. Recursos forestales e hídricos para la Real Armada durante el siglo XVIII en Guipúzcoa y Navarra. Tiempos modernos, 9(39), 426-455.

Aragón Ruano, R. (2019a). Un choque de jurisdicciones. Fueros y política forestal en el Pirineo occidental durante el siglo XVIII. Obradoiro de Historia Moderna, 28, 135-162.

Aragón Ruano, Á. y Riezu Elizalde, Ó. (2020). ¿Un proyecto quimérico? Suministros forestales desde los Pirineos occidentales para la Real Armada en el siglo XVIII. Studia Historica de Historia Moderna, 42(2).

Aranda y Antón, G. (1990). Los Bosques Flotantes; Historia de un roble del siglo XVIII. Madrid: Colección Técnica del ICONA.

Baroja, J. (1969). La hora navarra del siglo XVIII. Pamplona: Diputación foral.

Boterbloem, K. (2020). The dirty secret of Early Modern Capitalism. The global reach of the Dutch arms trade, warfare and mercenaries in the Seventeenth Century. Londres: Routledge.

Brandon, P. (2017). War, Capital and the Dutch State (1588-1795). Chicago: HaymarketBooks.

Chamorro Esteban, A. (2019). Bosques y galeras: la explotación maderera para la construcción naval en las Atarazanas de Barcelona (1573-1746). Tiempos modernos: Revista Electrónica de Historia Moderna, 9(39), 374-395.

Crespo Solana, A. (2002). Las comunidades mercantiles y el mantenimiento de los sistemas comerciales de España, Flandes y la República holandesa, 1648-1750. En M. Herrero y A. Crespo (coords.), España y las 17 provincias de los Países Bajos: una revisión bistoriográfica (XVI-XVIII), 2, 443-468.

Ediciones Universidad de Salamanca / 요 Stud. his., H. ${ }^{a}$ mod., 43, n. 1 (2021), pp. 195-226 
Crespo Solana, A. (2007). El comercio holandés y la integración de espacios económicos entre Cádiz y el Báltico en tiempos de guerra (1699-1723). Investigaciones de Historia Económica, 3(8), 45-76.

Crespo Solana, A. (2011). Elementos de transnacionalidad en el comercio flamenco-holandés en Europa y la Monarquía hispánica. Cuadernos de Historia Moderna, 10, 55-76.

Crespo Solana, A. (2014) A network-based Merchant Empire: Dutch Trade in the Hispanic Atlantic (1680-1740). En G. Oostindie y J. V. Roitman (eds.), Dutch Atlantic Connections, 1680-1800: Linking Empires, Bridging Borders (pp. 139-158). Leiden: Brill.

Crespo Solana, A. (2018). Cooperación y competencia político-económica en la larga duración: Holanda en la ruta del Mediterráneo (1621-1702). Pedralbes: Revista d'historia moderna, 38, 19-49.

De Pablo de la Fuente, P. (2020). Tu Regere Imperio Fluctus Hispane Memento: La aportación extranjera a la construcción naval dieciochesca. Una perspectiva comparativa y diacrónica. La Coruña: Universidad de La Coruña.

Dedieu, J. P. (2011). Les groupes financiers et industriels au service du roi. Espagne, fin XVIIe-début XVIIIe siècle. En A. Dubet, J. P. Luis (eds.), Les financiers et la construction de l'Etat - France, Espagne (XVIIe-XIXe siècle) (pp. 87-104). Rennes: Presses Universitaires de Rennes.

Delgado Ribas, J. M. (2018). La corrupción como mecanismo de fidelización. El caso de la Cataluña borbónica (1714-1770). En A. Coello y M. Rodrigo (eds.), La justicia robada. Corrupción, codicia y bien público en el mundo bispánico (siglos XVII-XX) (pp. 129-154). Barcelona: Icaria, Historia.

Dubet, A. (2008a). Un estadista francés en la España de los Borbones. Juan Orry y las primeras reformas de Felipe V(1701-1706). Madrid: Biblioteca Nueva.

Fernández Albaladejo, P. (1977). El decreto de suspensión de pagos de 1739: análisis y explicación. Moneda y Crédito, 142, 51-81.

Fernández Flórez, M. (2019). Controversias sobre los usos forestales en Cantabria durante la segunda mitad del siglo XVIII. Obradoiro de Historia Moderna, 28, 163-186.

Goodman, D. (1997). El poderío naval español. Historia de la Armada española del siglo XVII. Barcelona: Península.

Graham, A. (2018). Corruption and Contractors in the Atlantic World, 1754-1763. English Historical Review, 1-27.

Hamish, G. (2002). Profits and Privileges: Forest and Commercial Interests in Ancien Régime France. French History, 16(4), 381-401.

Hamish, G. (2009). Fleurs-de-lis in the forest: absolute monarchy and attempts at resource managment in eighteenth-century France. France History, 23(3), 311-335.

Hernández Escayola, M. ${ }^{a}$ C. (2004). Negocio y servicio: finanzas públicas y hombres de negocios en Navarra en la primera mitad del siglo XVIII. Pamplona: Eunsa.

Ibáñez Molina, M. (1985). Rentas provinciales, administración real y recaudadores en el reinado de Felipe V (1700-1739). Granada: Universidad de Granada.

Leonor Freire, C. (2009). State Monopoly or Corporate Business: Warfare in Early Modern Europe. Journal of European Economic History, 2, 219-261.

Ediciones Universidad de Salamanca / @@ Stud. his., H. ${ }^{a}$ mod., 43, n. 1 (2021), pp. 195-226 
López Arandia, M. (2018). Aprovisionando de madera el arsenal de Cartagena: el proyecto de Manuel Bernia y las flotaciones por el río Segura (1784-1793). Tiempos Modernos, 36(1), 127-168.

Maiso González, J. (1990). La difícil modernización de Cantabria en el siglo XVIII. Santander: Ayuntamiento de Santander.

Martí Fraga, E. (2019). Cataluña y la movilización de recursos militares para la expedición a Sicilia, 1718. Cuadernos de historia moderna, 44(1), 2019, 129-158.

Martínez González, A. (2013). Bosques y política naval atlántica: las reformas normativas e institucionales de José Patiño (1717-1736). Revista Hispanoamericana, 3, 1-26.

Martínez González, A. (2014). La elaboración de la Ordenanza de Montes de Marina, de 31 de enero de 1748, base de la política oceánica de la monarquía española durante el siglo XVIII. Anuario de Estudios Americanos, 71(2), 571-602.

Martínez González, A. (2015a). Las superintendencias de montes y plantios (1574-1748): derecho y politica forestal para las armadas en la Edad Moderna. Valencia: Tirant lo Blanch.

Martínez González, A. (2015b). Los asentistas de maderas, relaciones contractuales para las armadas hispánicas (siglos XVI-XVIII). En J. J. Iglesias (coord.), Comercio y cultura en la Edad Moderna, 2 (pp. 1195-1214). Sevilla: Universidad de Sevilla.

Matteson, K. (2015). Forests in Revolutionary France: Conservation, Community, and Conflict, 1669-1848. Cambridge: Cambridge University Press.

Merino, J. (1981). La Armada Española en el siglo XVIII. Madrid: Fundación Universitaría Española.

Odriozola Oyarbide, L. (1998). La construcción naval en el País Vasco. Siglos XVI-XVIII. Itsas Memoria. Revista de estudios maritimos del País Vasco, 2, 93-146.

Pérez Fernández, C. (2006). Patiño y las reformas de la Administración en el reinado de Felipe V. Madrid: Ministerio de Defensa-Instituto de Historia y Cultura Naval.

Pérez Sarrión, G. (2016). The Emergence of a National Market in Spain, 1650-1800: Trade Networks, Foreign Powers and the State. Londres: Bloomsbury Academic.

Pezzi Cristóbal, P. (2001). Proteger para producir. La política forestal de los Borbones españoles. Baetica. Estudios de Arte, Geografía e Historia, 23, 583-595.

Rahn Phillips, C. (2010). El Tesoro del San José. Muerte en el mar durante la Guerra de Sucesión Española. Madrid: Marcial Pons.

Riezu Elizalde, Ó. (2019). Almadias para la Armada. Pedro Vicente Gambra y la explotación de los bosques del valle de Roncal (siglo XVIII), TFM. Cádiz: Universidad de Cádiz.

Ruiz García, V. (2018). La provincia maritima del Segura (1733-1836) poder naval, explotación forestal y resistencia popular en la España del Antigno Régimen. Murcia: Universidad de Murcia.

Sánchez Camacho, A. (2020). Convergence of public and private agendas in the shaping of the early modern Hispanic Monarchy: an economic-based approach. Investigaciones de Historia Económica - Economic History Research, 16, 1-12.

Ediciones Universidad de Salamanca / 요 Stud. his., H. ${ }^{a}$ mod., 43, n. 1 (2021), pp. 195-226 
Sanz Ayán, C. (1992). Negociadores y capitales holandeses en los sistemas de abastecimientos de pertrechos navales de la monarquía hispánica durante el siglo XVII. Hispania: Revista española de historia, 52(182), 915-945.

Serrano Mangas, F. (1983). Los pertrechos extranjeros para los galeones de la Carrera de Indias en la segunda mitad del siglo XVII. Temas americanistas, 2, 21-26.

Serrano Mangas, F. (1992). Función y evolución del galeón en la carrera de Indias. Madrid: Mapfre.

Solbes Ferri, S. (2013) Campillo y Ensenada: el suministro de vestuarios para el ejército durante las campañas de Italia (1741-1748). Studia historica. Historia moderna, 35, 201-234.

Solbes Ferri, S. (2018) The Spanish monarchy as a contractor state in the eighteenth century: Interaction of political power with the market. Business History, 60(1), 72-86.

Solbes, S., Dubet, A., Bertrand, M., Torres, R. (2015). Gasto militar y agentes privados. La provisión de uniformes para el ejército español en el siglo XVIII. Tiempos modernos: Revista Electrónica de Historia Moderna, 8(30).

Tavárez Fidel, J. (2018). Colonial Economic Improvement: How Spain Created New Consulados to Preserve and Develop Its American Empire, 1778-1795. Hispanic American Historical Review, 98(4), 605-634.

Torres Sánchez, R. y Angulo-Morales, A. (2021). The Forgotten Collaboration: State and Society in the Mobilisation of Resources for War in the Early Modern Era. Ayer, 1 Forthcoming.

Torres Sánchez, R. (2006). The Failure of the Spanish Crown's Tobacco Tax Monopoly in Catalonia during the Eighteenth Century. The Journal of European Economic History, 35(1), 721-760.

Torres Sánchez, R. (2013). El precio de la guerra. El estado fiscal-militar de Carlos III. Madrid: Marcial Pons.

Torres Sánchez, R. (2015). Constructing a Fiscal-Military State in Eighteenth-Century Spain. Hampshire: Palgrave Macmillan, 117.

Torres Sánchez, R. (2016a) Alimentando a Marte: la política de suministros militares al ejército español en el XVIII. Cuadernos de Historia Moderna, 41(2), 373-389.

Torres Sánchez, R. (2016b). Military Entrepreneurs and the Spanish Contractor State in the Eighteenth Century. Oxford: Oxford University Press.

Torres Sánchez, R. (2018a). La monarchie espagnole \& le financement de la marine au XVIIIe siècle. En A. Guimerá y O. Chaline (dirs.), La Marine des Bourbons d'Espagne au XVIIIe siécle (pp. 53-76). Paris: Histoire Maritime, Presses de l'université ParisSorbonne.

Torres Sánchez, R. (2018b). El estado fiscal-naval de Carlos III. Los dineros de la Armada en el contexto de las finanzas de la Monarquía. En J. Marchena y J. Cuño, Vientos de Guerra. Apogeo y crisis de la Real Armada, 1750-1823 (pp. 329-435), 1. Madrid: Ediciones Doce Calles.

Torres Sánchez, R. (2021) Mercantilist Ideology versus Administrative Pragmatism: The supply of shipbuilding timber in eighteenth-century Spain. War E Society, 40(1).

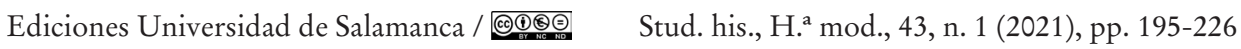


Torres Sánchez, R. y Díaz-Ordoñez, M. (2016). Los suministros militares y los empresarios navarros del siglo XVIII en la Hora Navarra. En A. Angulo y Á. Aragón (eds.), Recuperando el Norte. Empresas, capitales y proyectos atlánticos en la economía imperial hispánica (pp. 329-344). Bilbao: Universidad del País Vasco.

Trápaga Monchet, K. (2019). No es madera para vasallos, sino del rey: las políticas forestales de los Habsburgo en Portugal (1609-1640). Obradoiro de historia moderna, 28, 105-134.

Trindade, A. (2015). Bourbon naval policy, forestry and timber supply for shipbuilding in Andalusia (1700-1759) brief introductory research notes, R. y M. Varela (eds.), The management of Iberian forest resources in the Early Modern Shipbuilding: History and Archaelogy (pp. 57-63). Lisboa: Instituto de Arqueología e Paleociencias.

Urteaga, L. (1987) La tierra esquilmada. Ideas sobre la conservación de la naturaleza en la cultura española del siglo XVIII. Madrid: Ediciones del Serval.

Valdez Bubnov, I. (2011). Poder naval y modernización del estado: politica de construcción naval española (siglos XVI-XVIII). México: UNAM, Instituto de investigaciones históricas.

Valdez Bubnov, I. (2018), Shipbuilding administration under the Spanish Habsburg and Bourbon regimes (1590-1834): A comparative perspective. Business History, 60(1), 105-125.

Warde, P. (2006). Fear of Wood Shortage and the Reality of the Woodland in Europe, c.1450-1850. History Workshop Journal, 62(1), 28-57.

Wing, J. (2015) Roots of Empire. Forests and State Power in Early Modern Spain, c. 15001750. Boston: Brill.

Woolley, C. (2020). The Forests Cannot be Commons: Spanish Law, Environmental Change, and New Spain's Council on Forests. The Americas, 77(1), 41-71.

Ediciones Universidad de Salamanca / @@ Stud. his., H. ${ }^{a}$ mod., 43, n. 1 (2021), pp. 195-226 